\title{
Do human papilloma viruses play a role in the genesis of cutaneous malignancies?
}

\begin{abstract}
The role of human papillomavirus (HPV) infection in the genesis of cutaneous malignancies with special reference to cutaneous squamous cell carcinoma (SCC) remains a mystery. Recent evidence suggests that certain circumstances, such as allograft transplantation or genetic predisposition may allow infection with HPV to result in cutaneous malignancy.
\end{abstract}

Keywords: human papillomavirus, cutaneous malignancies, bak, viral genome, skin carcinogenesis
Volume 2 Issue I - 2018

\author{
Mohamed JEMF Mabruk \\ Department of Allied Health Sciences, Sultan Qaboos University, \\ Oman \\ Correspondence: Mohamed JEMF Mabruk, College of \\ Medicine and Department of Allied Health Sciences Allied \\ Health Sciences, Sultan Qaboos University, Al Khoudh, Muscat \\ 123, Oman, Tel +96824I43464, Fax +96824413419, \\ Emailmabruk@squ.edu.om
}

Received: October 12, 2017 | Published: February 02, 2018
Abbrevations: HPV, human papillomavirus; SCC, squamous cell carcinoma; EV, epidermodysplasia verruciformis; UV, ultraviolet; MAML-1, mastermind-like protein-1

\section{Introduction}

The human papillomavirus is a double-stranded DNA virus that infects the epithelial cells of skin and mucosa. ${ }^{1}$ The family of papillomaviridae consists of around 200 different human papillomavirus types. $^{2}$ The various types and subtypes of HPV are distinguished on the basis of their nucleic acid sequence. ${ }^{3}$

HPVs have been divided into 5 genera: Alpha-papillomavirus, Beta-papillomavirus, Gamma-papillomavirus, Mu-papillomavirus and Nu-papillomavirus. ${ }^{4,5}$ Members of the genus alpha HPV types are known to induce benign skin warts, genital warts and cervical cancer. ${ }^{6-8}$ Genus beta HPV were identified in flat warts and in cutaneous squamous cell carcinomas in epidermodysplasia verruciformis (EV) patients. ${ }^{910} \mathrm{EV}$ effected individuals are often infected with HPV types and many develop squamous cell carcinomas (SCCs) at body sites exposed to sunlight. ${ }^{11}$ EV specific HPV types include HPV5 and HPV8 and to a lesser extent HPV14, and HPV20. ${ }^{12,13}$ It has been suggested that, the increase of risk of cutaneous malignancies in sun exposed area in EV patients may indicate correlation between DNA damage induced by Ultraviolet irradiation (UV) and the infection with beta HPV virus. ${ }^{14-16}$

The prevalence of beta-HPV DNA was found to be higher in premalignant lesions and SCC in immunocompromised individuals in comparison to immune competent patients. ${ }^{17,18}$ The higher rate of cutaneous malignancies among immunocompromised patients suggests that HPV may play a role in the genesis of this type of malignancies.

Previous studies showed that HPV viral load is decreased during skin carcinogenesis and significantly higher in actinic keratosis than in SCC. ${ }^{14,19}$ This led to the suggestion that the virus may play a role in the early stages of SCC development and that the role of HPV would be initiation of malignancies rather than maintenance. ${ }^{14}$ This may indicate that the beta-HPV is playing a role in the initiation of malignancy by destabilizing the host genome by allowing the persistence of mutations that can drive tumorigenesis independently of the viral genome. ${ }^{20}$

\section{Discussion}

The HPV genome may explain how this mysterious virus may contribute to malignancy. It consists of approximately 8000 basepairs of double stranded, circular DNA that encode 9-10 open reading frames. ${ }^{21,22}$ The HPV genes are designated as early (E) and late (L) genes. $^{23}$ The early genes include E1, E2, E3, E4, E5, E6 and E7. ${ }^{21}$ The late genes include L1 and L2 genes. ${ }^{21}$ The L1 and L2 are major and minor capsid subunits respectively, and these are the structural proteins of the virion. ${ }^{21,22}$

The viral E1 and E2 proteins are responsible for perverting normal cellular processes in order to reproduce the viral genome. ${ }^{24}$ It has been shown that the early genes E6 and E7 encode the viral oncoproteins and they are the major transforming proteins of HPV. ${ }^{25,26}$

Other studies indicated that E5 of high risk types of HPV may play a role in the genesis of cervical cancer. ${ }^{27}$ The cellular target of E6 oncoprotein of alpha HPV in cervical cancer, is the tumor suppressor gene $p 53 . .^{26,28,29}$ The interaction of E6 oncoprotein with p53 results in its degradation and this may contribute to this type of malignancy. ${ }^{26}$

The E7 oncoprotein of alpha HPV in cervical cancer destabilize $\mathrm{pRB}$ through proteasomal degradation..$^{30}$ Deactivation of $\mathrm{pRB}$ results in displacement and thereby activation of E2F and thus contributing to cellular transformation. ${ }^{31}$ In regard to the oncoproteins E6 and E7 of beta HPVs, previous studies conducted in tissue culture and in transgenic mice showed clearly that E6 and E7 display transforming activities and the transformation activities are enhanced following exposure to Ultraviolet irradiation. ${ }^{32,33}$ These finding may further confirm the potential role of this HPV type in the genesis of cutaneous carcinogenesis. It has been proposed that the genus beta HPV E6 proteins inhibit at least some p53 target genes, although perhaps not by the same mechanism or to the same degree as the high-risk genus alpha HPV E6 proteins. $^{34}$ 
Furthermore, the E6 protein of cutaneous HPV types was shown to interfere with DNA damage repair ${ }^{35}$ and to inhibit apoptosis in keratinocytes in response to UV irradiation. ${ }^{36,37}$ The inhibition of apoptosis in keratinocytes was due to the capabilities of the E6 protein of HPV to degrade cell mediated apoptosis protein "Bak. ${ }^{38}$ " The capabilities of E6 protein of beta HPV to interfere to some degrees with the tumor suppressor gene $\mathrm{p} 53$ and with the DNA damage repair mechanisms and to inhibit the induction of apoptosis may explain how this virus may contribute to cutaneous malignancies.

The E6 protein of beta HPV is also shown to target MastermindLike protein-1 (MAML1), which is known to act as transcriptional co-activator for NOTCH protein. ${ }^{39,40} \mathrm{NOTCH}$ pathways play an important pro-differentiation role and have a tumor suppressing function in keratinocytes. ${ }^{41}$

On the other hand, the cutaneous beta HPV E7 oncoprotein is shown to bind pRB with lower efficiency than the high-risk HPV E7 proteins. ${ }^{42}$ However, this could be contributed to the type of beta HPV type involved, this suggestion was supported by previous work by Cornet I et al., ${ }^{43}$ who compared the properties of E6 and E7 oncoproteins from six uncharacterized beta HPVs types $(14,22,23,24,36,49)$ and found that only HPV49 E6 and E7 immortalized primary human keratinocytes and efficiently deregulated the $\mathrm{p} 53$ and pRb pathways. ${ }^{44}$

\section{Conclusion}

It appears that HPV is playing somehow a role in the initiation and genesis of cutaneous malignancies and more studies are needed in order to determine the carcinogenic properties of HPVs and their potential role in skin cancer development.

\section{Acknowledgement}

None.

\section{Conflicts of interest}

The author declares no conflicts of interest.

\section{References}

1. Stanley MA. Epithelial cell responses to infection with human papillomavirus. Clin Microbiol Rev. 2012;25(2):215-222.

2. Burk RD, Harari A, Chen Z. Human papillomavirus genome variants Virology. 2013;445(1-2):232-243.

3. Chan SY, Delius H, Halpern AL, et al. Analysis of genomic sequences of 95 papillomavirus types: uniting typing, phylogeny, and taxonomy. J Virol. 1995;69(5):3074-3083.

4. De Villiers EM, Fauquet C, Broker TR, et al. Classification of papillomaviruses. Virology. 2004;324(1):17-27.

5. Chouhy D, Bolatti EM, Pérez GR, et al. Analysis of the genetic diversity and phylogenetic relationships of putative human papillomavirus types. $J$ Gen Virol. 2013;94(Pt 11):2480-2488.

6. Bosch FX, Lorincz A, Muñoz N. The causal relation between human papillomavirus and cervical cancer. J Clin Pathol. 2002;55(4):244-265.

7. Viens LJ, Henley SJ, Watson M, et al. Human papillomavirus-associated cancers-United States, 2008-2012. Morb Mortal. 2016;65(26):661-666.

8. Bzhalava D, Guanb P, Franceschi S, et al. A systematic review of the prevalence of mucosal and cutaneous human papillomavirus types. Virology. 2013;445(1-2):224-231.
9. Orth G. Epidermodysplasia verruciformis: A model for understanding the oncogenicity of human papillomaviruses. Ciba Found Symp. 1986;120:157-174

10. Pfister H. Biology of epidermodysplasia verruciformis-associated HPV. Hautarzt. 2011;62(1):17-21.

11. Pfister H. Human papillomaviruses and skin cancer. Semin Cancer Biol. 1992;3(5):263-271.

12. Yutsudo M, Tanigaki $T$, Kanda $R$, et al. Involvement of human papillomavirus type 20 in epidermodysplasia verruciformis skin carcinogenesis. J Clin Microbiol. 1994;32(4):1076-1078.

13. Weissenborn SJ, Höpfl R, Weber F, et al. High prevalence of a variety of epidermodysplasia verruciformis-associated human papillomaviruses in psoriatic skin of patients treated or not treated with PUVA. J Invest Dermatol. 1999;113(1):122-126.

14. Howely PM, Pfister HJ. Beta Genus Papillomaviruses and skin cancer Virology. 2015;480:290-296.

15. Forslund $\mathrm{O}$, Iftner $\mathrm{T}$,Andersson $\mathrm{K}$, et al. Cutaneous human papillomaviruses found in sun-exposed skin: beta-papillomavirus species 2 predominates in squamous cell carcinoma. $J$ Infect Dis. 2007;196(6):876-883.

16. Hufbauer M and Akgül B. Molecular mechanisms of human papillomavirus induced skin carcinogenesis. Viruses. 2017;9(7):pii: E187.

17. Reusser NM, Downing C, Guidry J, et al. HPV Carcinomas in immunocompromised patients. J Clin Med. 2015;4(2):260-281.

18. Aldabagh B, Angeles JG, Cardones AR, et al. Cutaneous squamous cell carcinoma and human papillomavirus: is there an association? Dermatol Surg. 2013;39(1 Pt 1):1-23.

19. Wieland U, Kreuter A, Pfister H. Human papillomavirus and immunosuppression. Curr Probl Dermatol. 2014;45:154-165.

20. Wallace NA, Robinson K, Galloway DA. Beta human papillomavirus E6 expression inhibits stabilization of p53 and increases tolerance of genomic instability. J Virol. 2014;88(11):6112-6127.

21. Danos O, Katinka M, Yaniv M. Human papillomavirus 1a complete DNA sequence: a novel type of genome organization among papovaviridae. EMBO J. 1982;1(2):231-236.

22. Graham SV. Human papillomavirus: gene expression, regulation and prospects for novel diagnostic methods and antiviral therapies. Future Microbiol. 2010;5(10):1493-1506.

23. Zheng ZM and Baker CC. Papillomavirus genome structure, expression, and post-transcriptional regulation. Front Biosci. 2006;11:2286-2302.

24. Hoffmann R, Hirt B, Bechtold V, et al. Different modes of human papillomavirus DNA replication during maintenance. $J$ Virol. 2006;80(9):4431-4439.

25. Yim EK, Park JS. The role of HPV E6 and E7 Oncoproteins in HPVassociated cervical carcinogenesis. Cancer Res Treat. 2005;37(6):319-324.

26. Tomaić V. Functional Roles of E6 and E7 oncoproteins in HPV-induced malignancies at diverse anatomical sites. Cancers (Basel). 2016;8(10):95.

27. Liao S, Deng D, Zhang W, et al. Human papillomavirus 16/18 E5 promotes cervical cancer cell proliferation, migration and invasion in vitro and accelerates tumor growth in vivo. Oncol Rep. 2013;29(1):95-102.

28. Thomas M, Pim D, Banks L. The role of the E6-p53 interaction in the molecular pathogenesis of HPV. Oncogene. 1999;18(53):7690-7700.

29. Brimer N, Vande Pol SB. Papillomavirus E6 PDZ interactions can be replaced by repression of $\mathrm{p} 53$ to promote episomal human papillomavirus genome maintenance. J Virol. 2014;88(5):3027-3030. 
30. McLaughlin-Drubin ME, Münger K. The human papillomavirus E7 oncoprotein. Virology. 2009;384(2):335-344.

31. Jansma AL, Martinez-Yamout MA, Liao R, et al. The high-risk HPV16 E7 oncoprotein mediates interaction between the transcriptional coactivator CBP and the retinoblastoma protein pRb. J Mol Biol. 2014;426(24):4030 4048 .

32. Schaper ID, Marcuzzi GP, Weissenborn SJ, et al. Development of skin tumors in mice transgenic for early genes of human papillomavirus type 8 . Cancer Res. 2005;65(4):1394-1400.

33. Marcuzzi GP, Hufbauer M, Kasper HU, et al. Spontaneous tumour development in human papillomavirus type 8 E6 transgenic mice and rapid induction by UV-light exposure and wounding. J Gen Virol. 2009;90(Pt 12):2855-2864

34. White EA, Walther J, Javanbakht H, et al. Genus beta human papillomavirus E6 proteins vary in their effects on the transactivation of p53 target genes. Virol. 2014;88(15):8201-8212.

35. Giampieri S, Storey A. Repair of UV-induced thymine dimers is compromised in cells expressing the E6 protein from human papillomaviruses types 5 and 18. Br J Cancer. 2004;90(11):2203-2209.

36. Jackson S, Storey A. E6 proteins from diverse cutaneous HPV types inhibit apoptosis in response to UV damage. Oncogene. 2000;19(4):592-598.
37. Jackson S, Harwood C, Thomas M, Banks L, et al. Role of Bak in UVinduced apoptosis in skin cancer and abrogation by HPV E6 proteins. Genes Dev. 2000;14(23):3065-3073.

38. Underbrink MP, Howie HL, Bedard KM, et al. E6 proteins from multiple human betapapillomavirus types degrade Bak and protect keratinocytes from apoptosis after UVB irradiation. J Virol. 2008;82(21):10408-10417.

39. Brimer N, Lyons C, Wallberg AE, et al. Cutaneous papillomavirus E6 oncoproteins associate with MAML1 to repress transactivation and NOTCH signalling. Oncogene. 2012;31(43):4639-4646.

40. Meyers JM, Spangle JM, Munger K. The human papillomavirus type 8 E6 protein interferes with $\mathrm{NOTCH}$ activation during keratinocyte differentiation. J Virol. 2013;87(8):4762-4767.

41. Datto GP. Notch tumor suppressor function. Oncogene. 2008;27(38):51155123.

42. Cornet I, Bouvard V, Campo MS, et al. Comparative analysis of transforming properties of E6 and E7 from different beta human papillomavirus types. $J$ Virol. 2012;86(4):2366-2370.

43. Gage JR, Meyers C, Wettstein FO. The E7 proteins of the nononcogenic human papillomavirus type $6 \mathrm{~b}$ (HPV-6b) and of the oncogenic HPV-16 differ in retinoblastoma protein binding and other properties. $J$ Virol. 1990;64(2):723-730 